\title{
Catalytic Activity of Iron Doped Hexagonal Mesoporous Silica (Fe-HMS) for Degradation of Reactive Green-19 Dye in Water
}

\author{
Siti Norhannan Ashikin, H Amani and Ahmad Zuhairi Abdullah*
}

School of Chemical Engineering, Engineering Campus, Universiti Sains Malaysia, 14300 Nibong Tebal, Penang, Malaysia

\begin{abstract}
Iron nitrate supported hexagonal mesoporous (Fe-HMS) catalyst were successfully synthesized for Fenton-like oxidative degradation of Reactive Green-19 (RG19). Effects of pH, light intensity, catalyst amount, dye concentration, sensitizers, etc., were studied to optimize conditions for enhanced photo-catalytic activity. SEM, EDX, BET and UV-Vis (diffused reflectance mode) techniques were used to revealed the Fe-HMS physico-chemical properties. Kinetic study RG-19 treatment process at a reaction temperature $40^{\circ} \mathrm{C}, \mathrm{pH} 3,3 \mathrm{mgL}^{-1}$ of Fe-HMS, $50 \mu \mathrm{L}$ of $\mathrm{H}_{2} \mathrm{O}_{2}$, and $100 \mathrm{mgL}^{-1} \mathrm{of}^{-}$ dye were successfully carried out. The Fenton-like process correlation coefficient favors the first order kinetic model. COD and metal leaching analysis were done and results revealed that they were below DOE standard for effluent. Therefore, the treated water can safely discharge to the environment. The Fe-HMS catalyst reusability proved that it could be reused and has stability in reaction more than four cycles.
\end{abstract}

Keywords: Fenton-like catalysts; Fe-hms; Reactive green-19; Degradation process; Physic-chemical characterizes; Kinetic and reusability studies

\section{Introduction}

Based on the concern with regards to the environmental impact, the word is directed towards fulfilling the demands for safe wastewater disposal [1]. Treatment of dye pollutants must focus on reducing the concentration of the original dye compounds and their degradation products in wastewater. Related issues could include excessive production of sludge and required space for the physic-chemical treatment process, as well as longer detention time required in biological treatment process [2].

Mostly the dye pollutants produced by the textile industries show environmental and health issues [3]. These forms of pollutants are usually toxic and have to be treated before discharge [4]. Most of the methods used in the treatment of organic pollutants such as coagulation membrane, filtration, and biological treatment might also face other problems such as membrane fouling, formation of sludge, and incomplete mineralization [5]. Also, homogenous Fenton process could have certain drawbacks, as the Fe ion itself leads to several disadvantages as mentioned by Behnajady [6]. The sludge is often contaminated and it is classified as chemical sludge with Fe. In addition, this process leads to unwanted side reaction and has poor rate of reaction. Hence, new idea of heterogeneous Fenton process has been developed with the use of iron-free Fenton-like solid catalyst to replace $\mathrm{Fe}^{2+} / \mathrm{Fe}^{3+}[7]$. This heterogeneous Fenton reaction also takes place in the presence of hydrogen peroxide. However, due to lack of surface area and thicker pore wall, this single-chemical oxidation process still requires highly porous support materials to increase the catalytic activity [8]. Mesoporous materials that have pores diameters in the range of $2-50 \mathrm{~nm}$ are potential support material based on their unique properties such as controllable pore size and pore volume, high surface area, high ordered mesostructure, and high thermal stability to act as support materials in Fenton-like system [9-12].

Mesoporous silica in the form of two-dimensional hexagonal structure is formed from the arrangement of silica and the uniform mesopores with the presence of triblock copolymer Pluronic $P_{123}$, $(\mathrm{EO})_{20}(\mathrm{PO})_{70}(\mathrm{EO})_{20}$ as the structure-directing template [13]. The template is later removed by calcination process to create a material porous structure. Silica is frequently used in formation of mesoporous silica as it is inexpensive, chemically inert and safe to handle [14]. Hexagonal mesoporous silica, or also known as Santa Barbara
Amorphous, have been reported by Babaeiab et al. [15] to experience significant damage structure when exposed to high temperature. The secondary pore to its pores walls could disappear from the structure at high temperature and thinner wall of hexagonal mesoporous silica will be produced. Therefore, some modifications have been made by depositary metal iron in the framework of the catalyst $[16,17]$. This approach could potentially contribute to better efficiency in Fentonlike system. The addition of metal irons such as Fe has been reported to shows positive effect on the internal structure of HMS catalyst [18]. Since then, a lot research works have been carried out and the Fentonlike process employed to be the most attractive method to degrade dye pollutants with the use of supported catalyst [19].

In this study the efficiency of Fenton-like process towards the degradation of organic pollutants has been investigated under variety operating parameters such as the Fe-HMS dosage, initial $\mathrm{pH}$ of the solution, amount of $\mathrm{H}_{2} \mathrm{O}_{2}$ used concentration of dye, reaction temperature and the addition of salt. The extra of dye removal has been used to determine optimal conditions for the synthesis of the catalyst with regards to the acid concentration, Fe dosage and calcination temperature. The reaction kinetic with this type of catalyst has been investigated. Moreover, the catalyst stability and reusability have also been assessed to demonstrate its potential for application in wastewater treatment.

\section{Materials and Methods}

\section{Materials}

Iron nitrate $\mathrm{Fe}(\mathrm{NO})_{3} .9 \mathrm{H}_{2} \mathrm{O}(99 \%)$, Tetraethyl orthosilicate (TEOS) (99\%) and hydrochloric acid, $\mathrm{HCl}$ (37\%) were purchased from the Merck for catalyst preparation. A triblock copolymer, Pluronic $_{123},(\mathrm{EO})_{20}(\mathrm{PO})_{70}(\mathrm{EO})_{20}(99.99 \%)$ from Sigma Aldrich was

*Corresponding author: Ahmad Zuhairi Abdullah, School of Chemical Engineering, Engineering Campus, Universiti Sains Malaysia, 14300 Nibong Tebal, Penang, Malaysia, Fax: 04-594-1013; E-mail: chzuhairi@usm.my

Received March 21, 2016; Accepted March 31, 2016; Published April 08, 2016

Citation: Ashikin SN, Amani H, Abdullah Z (2016) Catalytic Activity of Iron Doped Hexagonal Mesoporous Silica (Fe-HMS) for Degradation of Reactive Green-19 Dye in Water. Nat Prod Chem Res 4: 215. doi:10.4172/2329-6836.1000215

Copyright: @ 2016 Ashikin SN, et al. This is an open-access article distributed under the terms of the Creative Commons Attribution License, which permits unrestricted use, distribution, and reproduction in any medium, provided the original author and source are credited. 
used as the structure-directing template. Reactive Green-19 (RG-19) $\left(\mathrm{C}_{40} \mathrm{H}_{23} \mathrm{Cl}_{2} \mathrm{~N}_{15} \mathrm{O}_{19} \mathrm{~S}_{6} \mathrm{Na}_{6}\right)$ dye was supplied from Merck Company with purity of more than $98 \%$ was dissolved in distilled water to be used as the pollutant.

\section{Synthesis of Fe-HMS catalysts}

The Fe-HMS catalysts were prepared with various dosages of iron nitrate and acid concentration [16,17]. Iron nitrate $\left(\mathrm{Fe}(\mathrm{NO})_{3} \cdot 9 \mathrm{H}_{2} \mathrm{O}\right)$ and tetraethyl orthosilicate (TEOS) were used as the iron precursor and silicon, respectively. Meanwhile, the non-ionic amphiphilic triblock copolymer Pluronic $\mathrm{P}_{123},(\mathrm{EO})_{20}(\mathrm{PO})_{70}(\mathrm{EO})_{20}$ acted as the structuredirecting template and the hydrochloric acid solution was used as the acidic medium for the synthesis.

In a typical in-situ synthesis, $4 \mathrm{~g}$ of surfactant were dissolved in 31 $\mathrm{ml}$ of water and then mixture was stirred for 2 hours. $70 \mathrm{~mL}$ of different $\mathrm{HCl}$ concentration was added into the mixture and was stirred for another 2 hours at room temperature. Then, after the dissolution of block copolymer, the additional of iron nitrate, $\mathrm{Fe}(\mathrm{NO})_{3} \cdot 9 \mathrm{H}_{2} \mathrm{O}$ was added and $11 \mathrm{~mL}$ of tetraethyl orthosilicate (TEOS) was added drop wise to the solution and left under stirring vigorously for 20 hours at $40^{\circ} \mathrm{C}$. Then, the resulting solution was transferred into an autoclave for the aging process for one day at $100^{\circ} \mathrm{C}$, under static condition. The solid product was then collected in the next filtration step. The precipitate was then left dry in an oven for 24 hours at $80^{\circ} \mathrm{C}$. Finally, the surfactant was removed by using calcination at $550^{\circ} \mathrm{C}$ for 6 hours.

\section{Characterization of the synthesized catalysts}

The catalysts were characterized using various techniques to study their respective physical and chemical characteristics. Scanning Electron Microscope (SEM) was used to collect the Fe-HMS surface images. The accelerating voltage and detector current used were at $15 \mathrm{kV}$ and $10 \mathrm{~mA}$, respectively. Energy Dispersive X-ray (EDX) spectrometer was also used in conjunction with SEM to determine the elemental composition of specific spots on the surface of the catalyst. OXFORD INCA 400 EDX system with operating voltages in the range of $0.1 \mathrm{kV}$ to $30 \mathrm{kV}$ was used, with $\mathrm{Mn} \mathrm{Ka}$ as the energy source. By using a Micrometrics, ASAP 2020 prepared at $77 \mathrm{~K}$, nitrogen adsorptiondesorption isotherms were obtained. The specific surface area and pore size distribution were calculated by using the Brunauer-Emmett-Teller Method (BET) and Barrett-Joyner-Halenda Method (BJH) respectively; in which adsorption branch of the isotherms is in the $\mathrm{BJH}$ method. The pore volume was then determined from the plotted graph of nitrogenadsorbed volume against relative pressure $[20,21]$.

\section{Catalytic activity of Fe-HMS catalysts}

The degradation of the RG19 dye as the model organic pollutant in this study was carried out based on the reaction the Fenton-like reaction involving hydrogen peroxide, $\left(\mathrm{H}_{2} \mathrm{O}_{2}\right)$ as the oxidizing agent. The preparation of the catalytic synthesis was as desirable in previous works [22,23], with some modifications in terms of the reaction temperature, initial pH of RG-19 solution, Fe-HMS catalyst loading, amount of $\mathrm{H}_{2} \mathrm{O}_{2}$ and initial concentration of dye.

$100 \mathrm{ml}$ of different concentrations of Reactive Green-19 dye solution was prepared in a series of $1000 \mathrm{ml}$ conical flasks by diluting the dye with $50 \mathrm{~mL}$ of deionized water. Next, the $\mathrm{pH}$ of the solution was adjusted to the desired values using $0.05 \mathrm{M}$ of HCL solution in order to study the effect of the degradation rate. Different amounts of $\mathrm{Fe}-\mathrm{HMS}$ catalyst and $\mathrm{H}_{2} \mathrm{O}_{2}$ solution were added simultaneously into the conical flask. The prepared conical flasks were placed in a water bath shaker at different reaction temperatures. Lastly, $5 \mathrm{~mL}$ of the samples were collected from the reaction vessels every 15 minutes, for up to 120 minutes for analysis.

The color removal was measured by using an UV-Vis spectrophotometer. The concentration of dye solution was taken at different reaction times. The degradation efficiency is calculated as in the following equation, where $\mathrm{C}_{0}\left(\mathrm{mgL}^{-1}\right)$ is the initial concentration and $\mathrm{C}_{\mathrm{t}}\left(\mathrm{mgL}^{-1}\right)$ is the dye concentration at time, $\mathrm{t}(\mathrm{min})$ :

$$
\text { Degradation efficiency }=\left(\frac{1-C_{t}}{C_{0}}\right) \times 100 \%
$$

The mineralization percentage efficiency (\%) is measured based on Chemical Oxygen Demand (COD). Atomic absorption spectrometer was used to measure the amount of Fe remained after going through degradation step. The standard iron ion solution was first prepared in $0.10 \mathrm{mgL}^{-1}$ of $\mathrm{HNO}_{3}$ solution to convert a calibration curve. The treated water was first filtered to remove the catalyst from the solution once the decolorization step was completed. Next, the sample was analyzed for the concentration of $\mathrm{Fe}$ ion.

\section{Catalyst stability}

Once the degradation process was completed, the dye solution was filtered and the solid product was collected to undergo the drying process in an oven $80^{\circ} \mathrm{C}$. The dye degradation process was repeated by using this catalyst in order to determine the catalyst stability and reusability.

\section{Kinetic studies of the Fenton-like system}

The experimental data were prepared by using 6 conical flasks containing mixtures undergoing different treatment. The kinetics equations derived from the first-order reaction and second-order reaction is used to plot the experimental data against the time taken in minutes. The regression analysis based on this reaction kinetics graph is then performed.

\section{Results and Discussion}

\section{Catalyst characterization}

Surface morphology analysis: The surface morphology of prepared catalysts was studied using a Scanning Electron Microscope (SEM). The SEM images show a huge difference in the morphological structure (Figure 1a). The morphology of synthesized catalyst without of $\mathrm{HCl}$ was rod-like and it changed to curved rope-like when $2 \mathrm{mgL}$ ${ }^{1} \mathrm{HCl}$ was used in the synthesized of the Fe-HMS catalyst. This was because of the presence of acid could result in agglomerated material on the surface as shown in Figure 1a and 1b. This result is considerable with the surface catalysis resulted that will be discussed later.

Energy Dispersive X-ray (EDX) analysis also was performed in continues with SEM to determine the chemical composition on the surface of the prepared catalysts. Table 1 presents atomic percentages of iron, silica, oxygen and carbon of the two catalysts i.e., Fe-HMS-0 $\mathrm{mgL}^{-1} \mathrm{HCl}$ and $\mathrm{Fe}-\mathrm{HMS}-2 \mathrm{mgL}^{-1} \mathrm{HCl}$. Fe elements contributed the lowest composition for both catalyst, followed up by $\mathrm{Si}$ and $\mathrm{C}$ elements, and the highest composition is $\mathrm{O}$ elements.

\begin{tabular}{|c|c|c|}
\hline \multirow{2}{*}{ Elements } & \multicolumn{2}{|c|}{ Concentration (wt. \%) } \\
\cline { 2 - 3 } & Fe-HMS-0 $\mathbf{~ m g L}^{-1} \mathbf{~ H C l}$ & Fe-HMS-2 $\mathbf{~ m g ~ L}^{-1} \mathbf{~ H C l}$ \\
\hline $\mathrm{Fe}$ & 0.17 & 1.29 \\
\hline $\mathrm{Si}$ & 7.90 & 19.45 \\
\hline $\mathrm{C}$ & 47.89 & 68.48 \\
\hline \multicolumn{2}{|r}{ Table 1: Chemical composition of the prepared catalysts. } \\
\hline
\end{tabular}




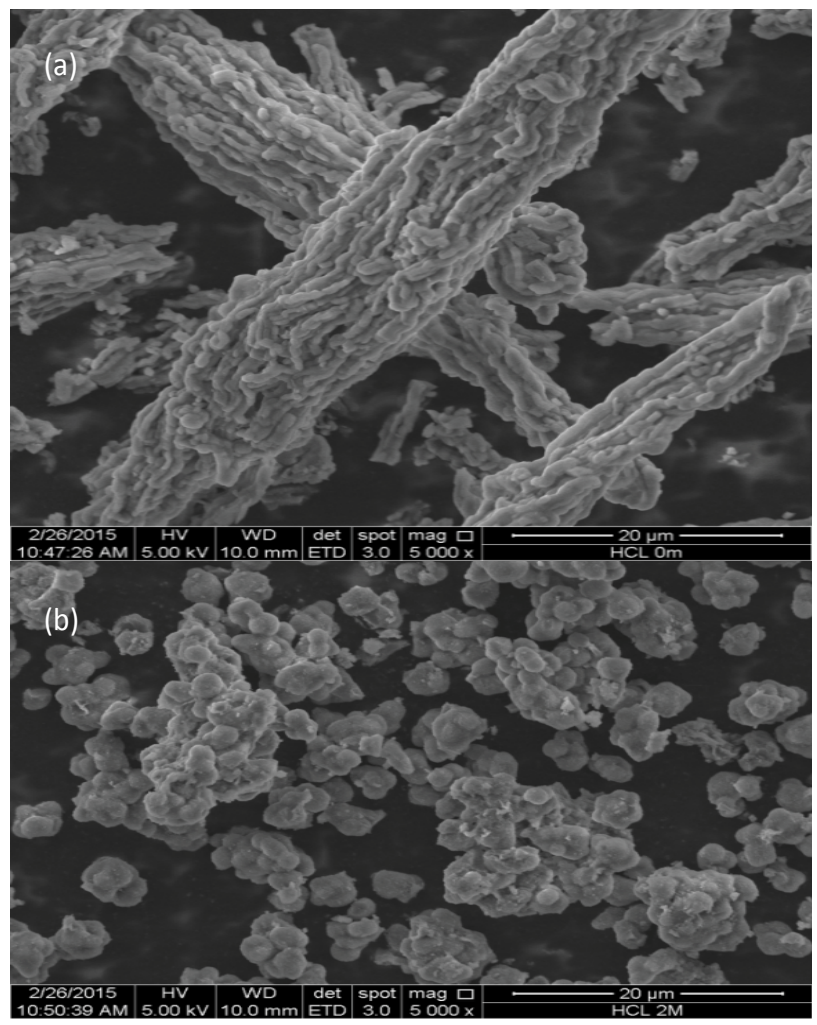

Figure 1a: SEM images of (a) Fe-HMS- $0 \mathrm{mgL}^{-1} \mathrm{HCl}$, and (b) Fe- $\mathrm{HMS}^{-2} \mathrm{mgL}^{-1} \mathrm{HCl}$

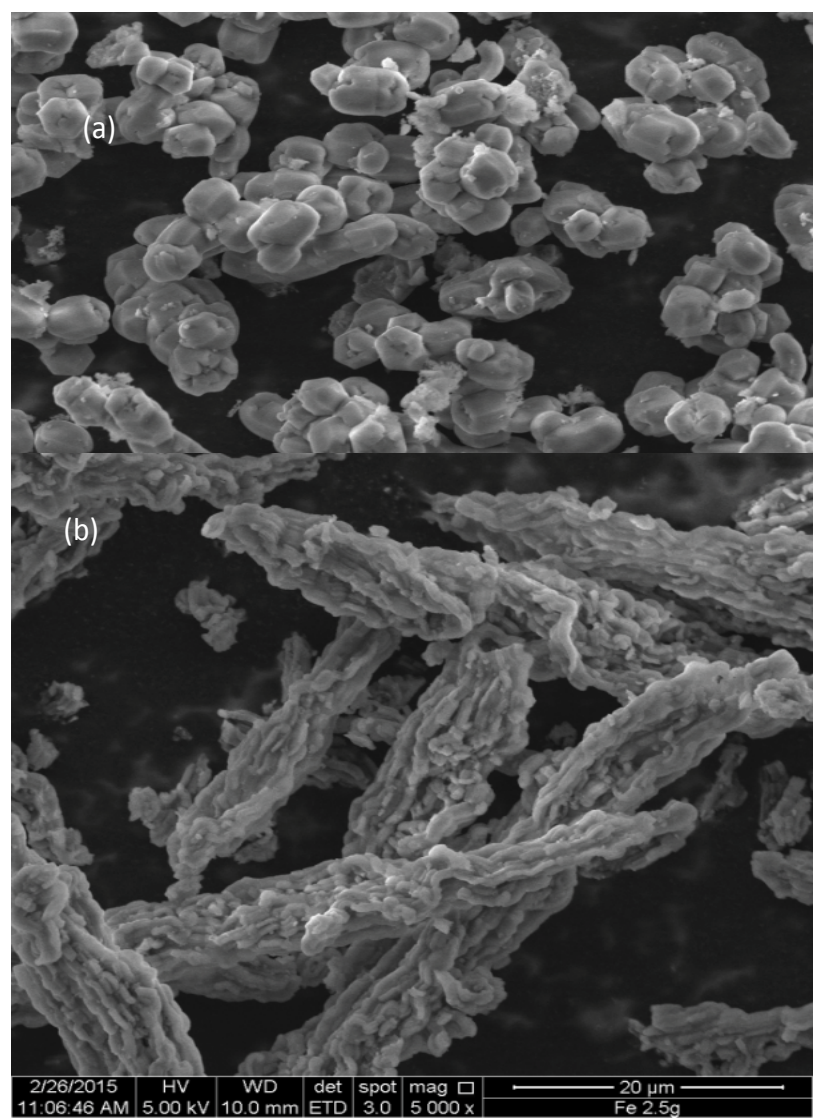

Figure 1b: SEM images of (a) Fe-HMS-3wt\%Fe and (b) Fe-HMS-13wt \% Fe.
The amount of Fe ions bonded on the surface of the prepared catalysts was found to increase with the presence of acid in the synthesize mixture. This is due to the fact that acid might block Fe ions from breaking into the structure of silica. On the other hand, the actual Fe concentrations in both samples are slightly different, in which higher Fe ions was detected in the catalyst without acid $\left(3.468 \mathrm{mgL}^{-1}\right)$ than catalyst with acid $\left(0.741 \mathrm{mgL}^{-1}\right)$.

Characteristics of Fe-doped catalysts with Fe dosage varied to two different levels were investigated by using surface morphology analysis to investigate $\mathrm{Fe}$ affect the morphology of the catalyst. Similarity, variation in the Fe dosage could leads to huge difference in the pore structure. As seen in Figure 2b, a curved rope-like material is clearly seen at lower Fe loading ( 3 wt. Fe). The change of Fe loading from the previous preparation of catalyst (change in acid concentration) has similar texture with the original catalyst without acid. It may be indicates the presence of similar microstructure. However, with higher loading of Fe, the morphology of Fe-HMS changes to rod-like material as shown in Figure $2 b$.

Surface analysis: Structural characteristics of Fe-HMS catalyst without and with the presence of acid were studied based on $\mathrm{N}_{2}$ adsorption-desorption at $77 \mathrm{~K}$. Based on the results shown in Table 2 and Figure $2 \mathrm{a}$ and $2 \mathrm{~b}$, the presence of acid has significantly influenced the physical properties of both samples. It could be detected that an adsorbate monolayer was formed for both catalysts, followed by the multilayer formation at relative high pressure of 0.5 to 0.8 for the sample without acid and within range between 0.6 and $0.8 \mathrm{P} / \mathrm{P}_{0}$ for the other sample. The increase in the $\mathrm{P} / \mathrm{P}_{0}$ that there was a decrease in pore size. This can be seen in the BET surface area in which the catalyst without acid has to form multilayer smaller pore size than suggested catalyst the one with acid. Both samples show typical type-IV isotherm in Figure 2b, mainly due to the capillary condensation and desorption of nitrogen. According to IUPAC classification [19-26], this type of hysteresis with loop and the shift of sharp inflection of $\mathrm{P} / \mathrm{P}_{0}$ are typical for 2D-hexagonal mesoporous material.

The pore size distributions in Figure $2 \mathrm{~b}$ indicate that both mesoporous catalysts had narrow and rather wide distribution. Additionally, a wider distribution can be noticed in the case of the catalyst pore size to indicate that the volume of mesoporous was higher compared to the catalyst with acid with a difference of 0.023 $\mathrm{nm}$. The total pore volume indeed was found to increase when acid was used in the synthesis as supported by result in Figure $2 \mathrm{~b}$ and Table 2. Both samples show maximum symmetric peaks at about $6 \mathrm{~nm}$, but the intensity of Fe-HMS- $2 \mathrm{mgL}^{-1} \mathrm{HCl}$ peak is higher compared to that of Fe-HMS- $0 \mathrm{mgL}^{-1} \mathrm{HCl}$, which reveals clearly suggests larger pore volume.

It should be noted that the BET surface area of Fe-HMS- $0 \mathrm{mgL}^{-1}$ $\mathrm{HCl}$ catalyst was slightly higher $(646 \mathrm{~nm})$ than that of Fe-HMS- $2 \mathrm{mgL}^{-1}$ $\mathrm{HCl}$ catalyst $(601 \mathrm{~nm})$. The rod-like material as seen in the SEM images in Figure 1a by the catalyst without acid suggested that its surface area was larger compared to the other catalyst (curved-rope material). This is might due to thinner wall that resulted with the use of acid in the synthesis of Fe-HMS framework. The total pore volume was inversely proportional to the surface area as shown in Table 3. The total pore volume of Fe-HMS- $0 \mathrm{mgL}^{-1} \mathrm{HCl}$ was smaller compared to that of $\mathrm{Fe}$ HMS- $2 \mathrm{mgL}^{-1} \mathrm{HCl}$, with a difference of $0.01 \mathrm{~cm}^{3} \mathrm{~g}^{-1}$ only. On the other hand, the range of pore size for the mesoporous material is within 2 up to $50 \mathrm{~nm}$, and thus, the $\mathrm{BJH}$ pore sizes shown in Table 3 are acceptable. Both catalysts had pore sizes above $2 \mathrm{~nm}$ or more accurately; $5 \mathrm{~nm}$ for the Fe-HMS- $0 \mathrm{mgL}^{-1} \mathrm{HCl}$ and $6 \mathrm{~nm}$ for the Fe-HMS- $2 \mathrm{mgL}^{-1} \mathrm{HCl}$. 


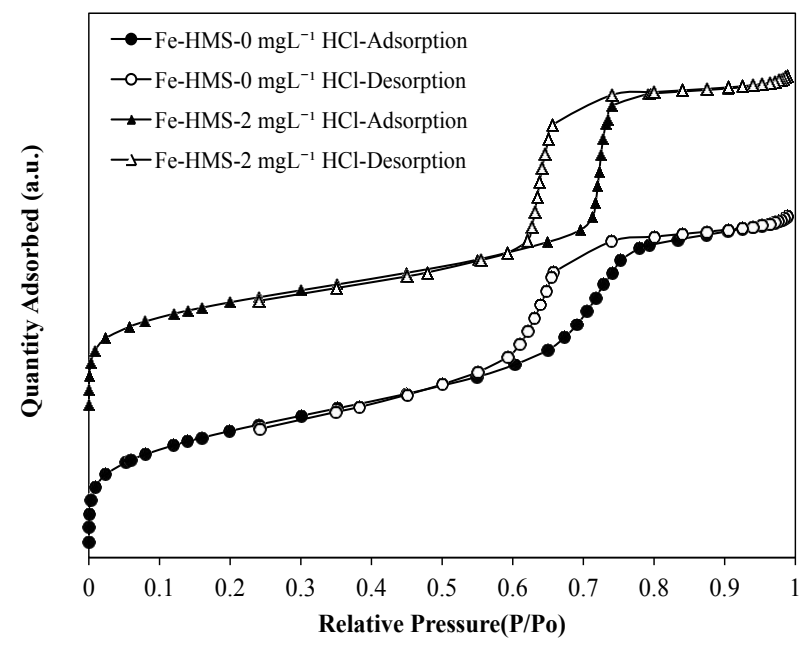

Figure 2a: $\mathrm{N}_{2}$-adsorption-desorption isotherms of Fe-HMS catalysts.

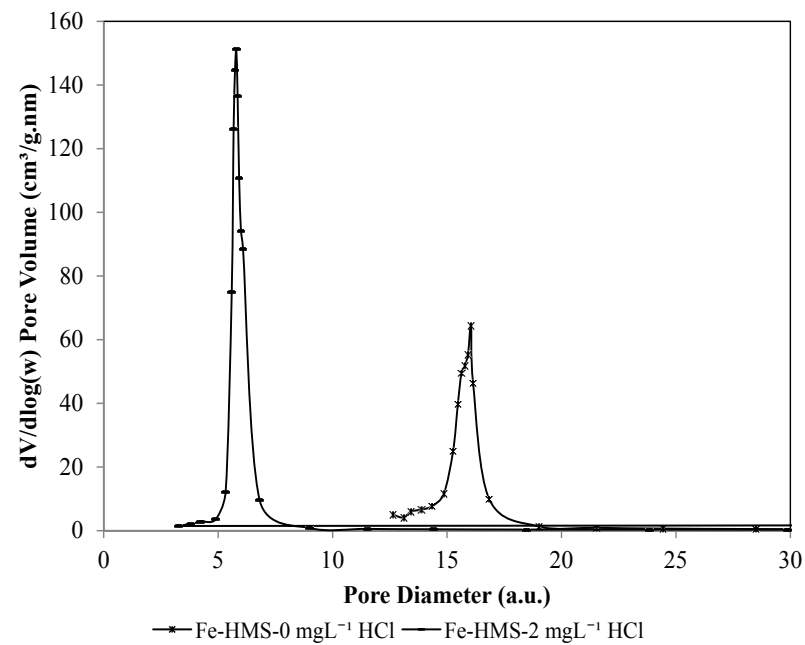

Figure 2b: Pore size distribution of Fe-HMS catalysts.

\section{Performance in catalytic degradation of RG-19}

The first experimental were carried out without heterogeneous catalyst (blank sample), but with the presence of hydrogen peroxide only. Figure 3a shows reaction between dye molecules and hydroxyl radical as Reactive Green-19 dyes under heterogenous $14 \%$ decolorization within 120 minutes. This clearly suggests the role of catalyst itself to increase the rate of reaction. The decolorization of the dye done to absorption process was studied for each experiment in which the process was allowed to occur the first 15 minutes (the figure shows -15 minutes). For each experimental gave very low degree of decolorization (lower than 1\%) to indicate poor adsorption of the dye by the catalysts. As such, decolorization should be mainly attributed to the Futon-like reaction.

Results in Figure 3a suggest that concentration of hydrochloric acid positively affected on the degradation of Reactive Green-19 dye. Higher concentration of hydrochloric acid increscent improved color removal. Catalyst with no acid clearly had slower reaction compared to others with only $34.24 \%$ of decolorization within 120 minutes of reaction. The higher amounts of hydrochloric acid used in synthesis of Fe-doped HMS catalyst resulted in the highest catalytic activity with $95 \%$ color removal in 120 minutes. In the catalyst synthesis, hydrochloric acid is needed in the hydrolysis step of teraethoxysilane (TEOS) and it should be suitable for the assembly of triblock polymer P123, as there is a combination of electrostatic and hydrogen-bonding interactions.

However, improvement in the decolorization by catalysts with between $1.5 \mathrm{mgL}^{-1}$ and $2 \mathrm{mgL}^{-1}$ was rather small. As such, further increase in the amount of HCL used beyond $2 \mathrm{mgL}^{-1}$ should not be attempted.

\section{Effect of Fe loading in Fe-doped HMS as catalytic activity}

The positive effect increasing dosage of $\mathrm{Fe}$ in the catalyst as seen in Figure $3 \mathrm{~b}$ suggests the complementary roles of Fe with HMS catalyst. Active sites are needed for the acid while HMS played the role as a good

\begin{tabular}{|c|c|c|c|c|c|}
\hline \multirow[t]{2}{*}{ Catalyst } & \multirow{2}{*}{$\begin{array}{c}\text { BET } \\
\text { Surface } \\
\text { Area } \\
\left(\mathbf{m}^{2} \mathbf{g}^{-1}\right)\end{array}$} & \multirow{2}{*}{$\begin{array}{l}\text { BJH } \\
\text { Pore } \\
\text { Size } \\
(\mathrm{nm})\end{array}$} & \multirow[b]{2}{*}{$\begin{array}{l}\text { Micropore } \\
\text { Volume }\end{array}$} & \multicolumn{2}{|c|}{ Pore Volume $\left(\mathrm{cm}^{3} \mathrm{~g}^{-1}\right)$} \\
\hline & & & & $\begin{array}{l}\text { Mesopores } \\
\text { Volume }\end{array}$ & $\begin{array}{l}\text { Total Pore } \\
\text { Volume }\end{array}$ \\
\hline Fe-HMS-0 mgL-1 $\mathrm{HCl}$ & 646 & 5 & 0.023 & 0.746 & 0.769 \\
\hline Fe-HMS-2 mgL-1 $\mathrm{HCl}$ & 601 & 6 & 0.056 & 0.722 & 0.779 \\
\hline
\end{tabular}

Table 2: Surface analysis of the prepared catalyst.

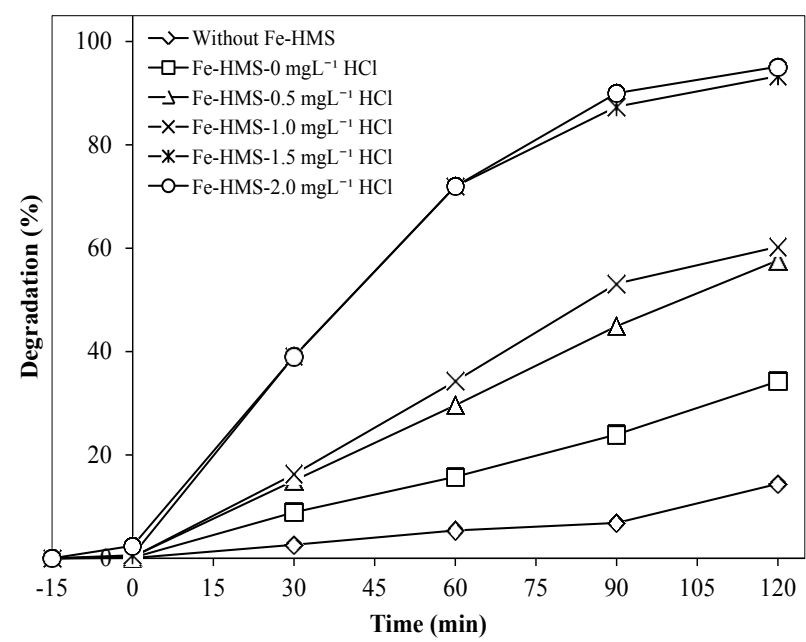

Figure 3a: Effect of acid concentration on the development of Fe-HMS catalyst. Catalyst Dosage $=1 \mathrm{mgL}^{-1}, \mathrm{pH} 3, \mathrm{~T}=30^{\circ} \mathrm{C},\left[\mathrm{H}_{2} \mathrm{O}_{2}\right]=100 \mu \mathrm{L},[\mathrm{RG}-19]=100 \mathrm{mgL}^{-1}$.

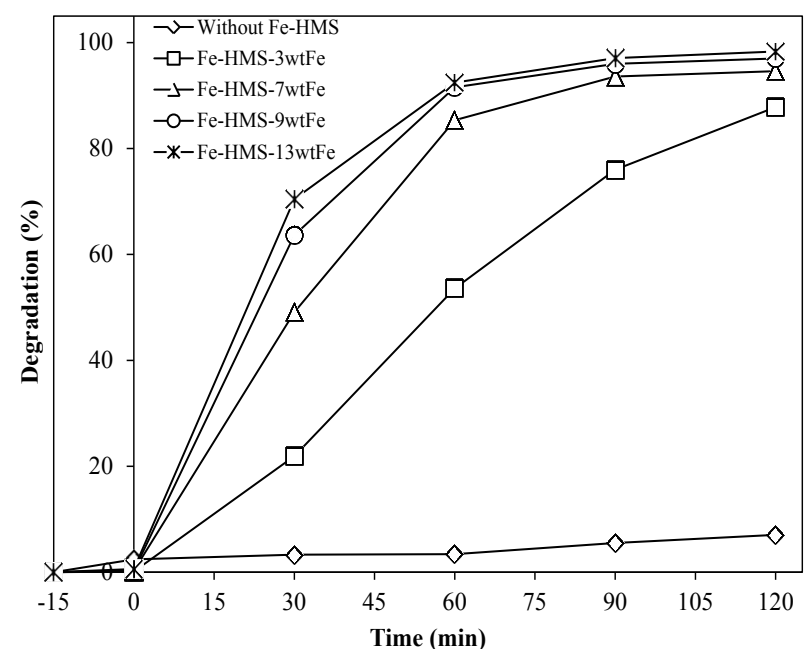

Figure 3b: Effect of Fe loading on the development of Fe-HMS catalyst (Catalyst Dosage $\left.=1 \mathrm{mgL}^{-1}, \mathrm{pH} 3, \mathrm{~T}=30^{\circ} \mathrm{C},\left[\mathrm{H}_{2} \mathrm{O}_{2}\right]=100 \mu \mathrm{L},[\mathrm{RG}-19]=100 \mathrm{mgL}^{-1}\right)$. 
support material reaction. Erdem et al. [24] outlined that metal ions itself are involved in self-assembly process as protons. Therefore, the reducing amount of Fe might affect the hydrogen bond in formation of meso-structured, as highlighted in the previous section. In addition, catalytic performance of modified Fe-HMS catalyst was better with the presence of higher loading of Fe (Figure 3b). Within 60 minutes of reaction, most of the catalysts (with Fe loading higher than 9-wt\%Fe) achieved approximately $90 \%$ of decolorization, while Fe-HMS-7wt $\% \mathrm{Fe}$ achieved $85 \%$ decolorization and Fe-HMS 3 wt $\%$ Fe could only managed to achieve $53.59 \%$ decolorization.

The increase in the Fe loading from $7 \mathrm{wt} \%$ to $13 \mathrm{wt} \%$ resulted in only a little improvement in catalyst activity. However, considerate potential loading of $\mathrm{Fe}$ in the process, the highest $\mathrm{Fe}$ ion (Fe-HMS$13 \mathrm{wt} \% \mathrm{Fe}$ ) was taken as the loading to be further investigated in the following section.

\section{Effect of operating conditions on catalytic activity}

To find the optimal parameters for best efficiency of Fenton-like oxidation, effects of reaction temperature, initial $\mathrm{pH}$ of dye, Fe-HMS loading, hydrogen peroxide dosage, and initial concentration of dye and addition of salt were studied.

Effect of reaction temperature: The effect of temperature on effectiveness of Fenton-like oxidation was investigated in the $25^{\circ} \mathrm{C}$ -

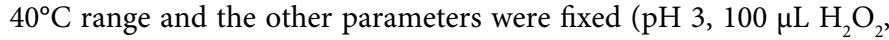
$100 \mathrm{mgL}^{-1}$ of dye, and $1 \mathrm{mgL}^{-1}$ of Fe-HMS catalyst). In the first -15 the adsorption of Reactive Green-19 dye was formed to be minimum with decolorizations below 1\%. Thus, Fe-HMS catalyst was conducted to play an important role in removal of the dye from the solution.

The run conducted at $25^{\circ} \mathrm{C}$ showed relatively lower removal. The highest decolorization was achieved $96.4 \%$ within 120 minutes. For the runs at $35^{\circ} \mathrm{C}$ and $40^{\circ} \mathrm{C}$, decolorizations of nearly $99 \%$ were achieved in the same direction. Previous researchers report that the optimal temperature for the process was below $45^{\circ} \mathrm{C}$ [25]. The generation rate of hydrogen peroxide from the high temperature could accelerate the effectiveness of the Fenton-like oxidation. The increase in the temperature also provided more energy for the dye molecules to overcome the interaction between them. Therefore, positive effect on treatment efficiency can be clearly seen in Figure $3 c$ as the decolorization increased with the increase in the temperature. It was proven that at high temperature $\left(40^{\circ} \mathrm{C}\right)$, shorter period of time to reach approximately $98 \%$ degradation within just 60 minutes of reaction.

As presented in Table 3, the thermodynamic parameters of the catalytic decolorization of Reactive Green 19 dye are summarized for both Eyring and Arrhenius equations. The positive value of Gibbs free energy, $\Delta \mathrm{G}^{\circ}$ indicates that the oxidative reaction using the Fentonlike reagent is non-spontaneous in nature. The activation energy (Ea) was calculated from the Arrhenius plot is low $\left(37.0 \mathrm{~kJ} \mathrm{~mol}^{-1}\right)$ with the presence of Fe-HMS catalyst. Olajire et al. [1] reported that metal activation significantly reduce the activation energy in compared to the run in the absence of a catalyst.

The Fenton oxidation is an endothermic process and results in Table 3 are consistent with reported area $[1,26]$. The positive value of enthalpy, $\left(\Delta \mathrm{H}^{\circ}\right)$ suggests that the process is an endothermic one. There increase of the decolorization with the increase in the reaction temperature also correctly suggest that it is an endothermic process (Figure $3 \mathrm{c}$ ). Therefore, the results in Table 3 are valid theoretically and experimentally. Next, there was a decrease in the degree of of randomness as the value of entropy $\left(\Delta S^{\circ}\right)$ is negative [27].
Effect of initial $\mathbf{p H}$ of reactive green-19: $\mathrm{pH}$ plays an important role as industrial effluent could have variable $\mathrm{pH}$ value that may affect the reaction mechanism, especially in production of hydroxyl radicals. A series of blank run (without catalyst) was first conducted within the first 15 minutes ( -15 minutes on the graph) to prove the effectiveness of the Fenton-like reagent. A sluggish activity compared to the next 120 minutes suggested that the reaction was way better with the presence of $\mathrm{Fe}$ ions.

Figure $3 \mathrm{~d}$ shows that the decolorization efficiency was high in strong acidic conditions ( $\mathrm{pH} 2 \sim \mathrm{pH} 3$ ) of compared in weak acidic conditions $(\mathrm{pH} 4 \sim \mathrm{pH}$ 6). At initial $\mathrm{pH}$ value of 2.00 and 3.00, the decolorization efficiencies were above $96 \%$ within 60 minutes as compared to the slower reaction rate in weak acidic conditions. Higher

\begin{tabular}{|c|c|c|c|c|}
\hline & $\Delta \mathbf{G}^{\circ}\left(\mathbf{k J ~ m o l}^{-1}\right)$ & $\mathrm{Ea}\left(\mathrm{kJ} \mathrm{mol}^{-1}\right)$ & $\Delta \mathrm{H}^{\circ}\left(\mathrm{kJ} \mathrm{mol}^{-1}\right)$ & $\Delta \mathbf{S}^{\prime}\left(\mathrm{J} \mathrm{mol}^{-1} \mathrm{~K}^{-1}\right)$ \\
\hline Temp 25 & 8.93372 & \multirow[t]{3}{*}{37.0147} & \multirow[t]{3}{*}{34.4831} & \multirow[t]{3}{*}{-0.1588} \\
\hline Temp 35 & 8.09186 & & & \\
\hline Temp 40 & 7.49284 & & & \\
\hline
\end{tabular}

Table 3: Thermodynamic parameters for the catalytic degradation of RG19 through the Fenton-like reaction.

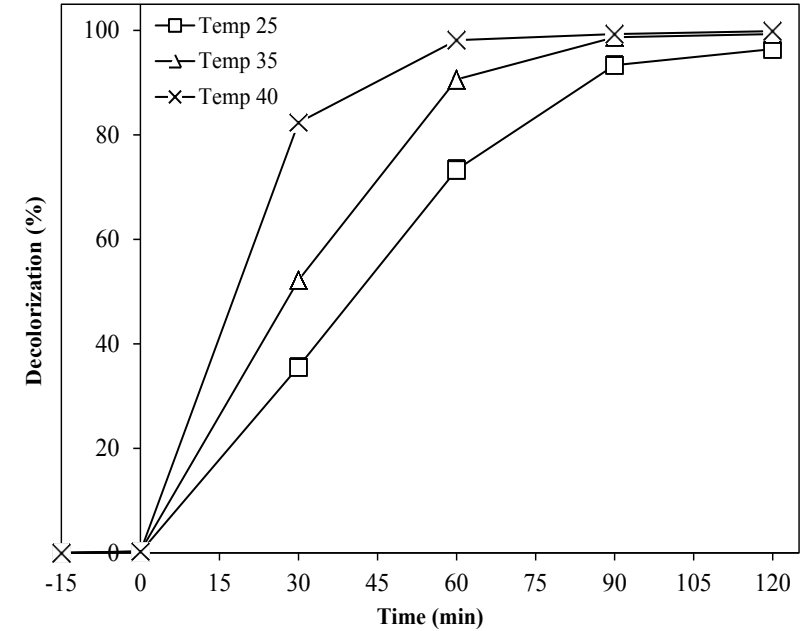

Figure 3c: Effect of temperature on catalytic degradation of RG-19 (Catalyst Dosage $=1 \mathrm{mgL}^{-1}, \mathrm{pH} 3,\left[\mathrm{H}_{2} \mathrm{O}_{2}\right]=100 \mu \mathrm{L},[\mathrm{RG}-19]=100 \mathrm{mgL}^{-1}$ ).

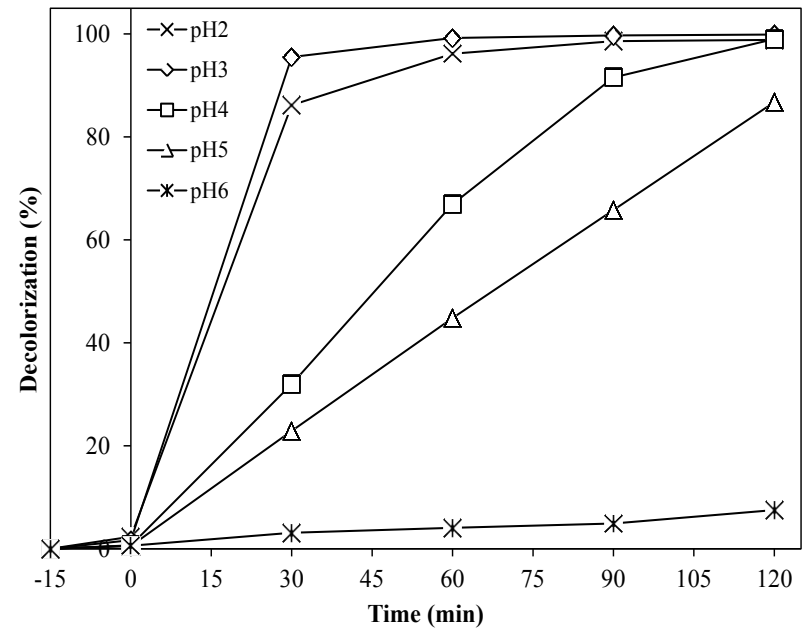

Figure 3d: Effect of initial pH of dye on catalytic degradation of $\mathrm{RG}-19$. ( $T=40^{\circ} \mathrm{C}$, Catalyst Dosage $\left.=1 \mathrm{mgL}^{-1},\left[\mathrm{H}_{2} \mathrm{O}_{2}\right]=100 \mu \mathrm{L},[R \mathrm{RG}-19]=100 \mathrm{mgL}^{-1}\right)$. 
$\mathrm{pH}$ leads to the decreasing oxidation potential of hydroxyl radicals and while causing $\mathrm{Fe}^{3+}$ to undergo precipitate reduced the concentration of $\mathrm{Fe}^{3+}$ in the dissolved state. This could be observed in the figure. Within 120 minutes the run at $\mathrm{pH} 6$ reached only $7.5 \%$ decolorization efficiency while at $\mathrm{pH} 5$ reached $79.2 \%$.

Nonetheless, there is a slightly difference between decolorization efficiency at $\mathrm{pH} 2$ and $\mathrm{pH} 3$. $\mathrm{pH} 3$ clearly showed fastest rate of reaction to remove the color almost completely. Thus, it can be concluded that too acidic solution would reduce the effectiveness of the Fenton-like process. As a result, the optimal $\mathrm{pH}$ was obtained at $\mathrm{pH} 3$. Several literatures [28,29] also reported similar results with other model components. They also achieved above $95 \%$ color removal at $\mathrm{pH} 3$. In addition, [1,27] found that the increase in the $\mathrm{pH}$ above 1.45 would decrease degradation efficiency in the case of Methylene Blue dye.

Effect of Fe-HMS catalyst loading: Effect of Fe-HMS catalyst loading on the Fenton-like oxidation were also investigated with variable catalyst loading $\left(0.5,1.5,3.0,5.0\right.$ and $1 \mathrm{mgL}^{-1}$ catalyst loading)

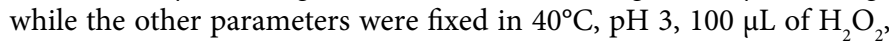
and $100 \mathrm{mgL}^{-1}$ of Reactive Green-19 dye. Based on Figure 3e, the absence of solid (Fe-HMS) catalyst caused poor rates of reaction with the highest degradation percentage is about $2.98 \%$ at catalyst loading of 5.0 while $0.5 \mathrm{mgL}^{-1} \mathrm{Fe}$ catalyst only achieve $0.12 \%$ of decolorization.

From previous section, only run at $\mathrm{pH} 2$ and $\mathrm{pH} 3$ achieved more than $80 \%$ of decolorazation in 30 minutes. In this study, $0.5 \mathrm{mgL}^{-1}$ of Fe catalyst loading reacted almost $90 \%$ in 30 minutes. In 90 minutes, almost complete decolorization was achieved. Additionally, it can be seen that at 90 minutes, $3 \mathrm{mgL}^{-1} \mathrm{Fe}$ loading reached its maximum decolorazation first, followed by $5 \mathrm{mgL}^{-1} \mathrm{Fe}$. The decolorization by 5 $\mathrm{mgL}^{-1} \mathrm{Fe}$ only increased very slightly from 60 minutes to 90 minutes of compared to that with $3 \mathrm{mgL}^{-1} \mathrm{Fe}$. Results in Figure 3e suggest that even with a small amount of iron loading $\left(0.5 \mathrm{mgL}^{-1} \mathrm{Fe}-\mathrm{HMS}\right.$ catalyst $)$, the decolorazation obtained within 30 minutes was nearly $90 \%$.

Based on Ertugay and Acar [9], the addition of $\mathrm{Fe}^{3+}$ ions to the reaction system should not exceed $3 \mathrm{mgL}^{-1}$. At higher Fe loading, brownish particles appeared and it could block the adsorption needed for the Fenton-like process. This contradicts with experimental results in this study as the decolorization continued to increase with increase in the Fe catalyst loading $[9,29]$.

In a nutshell, higher amount of Fe loading adding up to the reaction will accelerate the reaction with hydrogen peroxide to produce more hydroxyl radicals. The optimal condition was achieved at $3 \mathrm{mgL}^{-1}$ of Fe catalyst loading where the decolorization efficiency reached almost $99 \%$, within 90 minutes.

Effect of hydrogen peroxide dosage: Based on the following reaction, the number of hydroxyl radicals should increases with the increase in the of hydrogen peroxide dosage.

$$
\mathrm{H}_{2} \mathrm{O}_{2}+\mathrm{HO} \bullet \rightarrow \mathrm{H}_{2} \mathrm{O}+\mathrm{HO}_{2} \bullet
$$

In order to prove this relationship a series of experiments were performed by varying the dosage of hydrogen peroxide $(25,50,150$, 200 , and $300 \mu \mathrm{L}$ ). The initial $\mathrm{pH}$ was kept at 3 with $3 \mathrm{mgL}^{-1}$ of Fe loading, and the reaction temperature was set at $40^{\circ} \mathrm{C}$. In the first -15 minutes, all runs had almost the similar performance, approximately above $1.4 \%$ of decolorization. The presence of a Fe-HMS catalyst as clearly increased the treatment efficiency.

The data obtained from this section are slightly different from those in earlier section. Results in Figure $3 \mathrm{f}$ indicate that the increase in the hydrogen peroxide dosage improved the decolorization efficiency, which concludes that the hydroxyl radicals did affect the process. Results in the first 15 minutes suggest that hydrogen peroxide dosages above of $150 \mu \mathrm{L}$ had similar efficiency, with 86,81 and $75 \%$ of decolorization efficiency, followed up by $50 \mu \mathrm{L}$ of $\mathrm{H}_{2} \mathrm{O}_{2}$ with $54 \%$ and the slowest reaction was shown by the run with $25 \mu \mathrm{L}$ of $\mathrm{H}_{2} \mathrm{O}_{2}$ (21\%). Within 60 minutes, $50 \mu \mathrm{L}$ of $\mathrm{H}_{2} \mathrm{O}_{2}$ caused the highest reaction (99.9\%). The increase in the $\mathrm{H}_{2} \mathrm{O}_{2}$ dosage would lessen the efficiency of the reaction, and this might be due to the scavenger effect on the hydroxyl radicals. Besides, hydrogen peroxide dosages exactly $50 \mu \mathrm{L}$ could have reached their equilibrium within 45 minutes. However, from the literature Ertugay and Acar [9] mentioned that the addition of more than $125 \mu \mathrm{L}$ of $\mathrm{H}_{2} \mathrm{O}_{2}$ would reduce the color removal by about $34 \%$. This might due to the difficulties of several structures of dye molecules to be attacked by hydroxyl radicals. In this study, $50 \mu \mathrm{L}$ of $\mathrm{H}_{2} \mathrm{O}_{2}$ was chosen as the optimal for this parameter to be used in the subsequent stage [9].

Effect of initial concentration of dye: The first -15 minutes on Figure $3 \mathrm{~g}$ indicate slow progression of reaction for 4 samples with different initial dye concentrations. The highest dye concentration (120 $\mathrm{mgL}^{-1}$ ) resulted in an increase only about $1.12 \%$ hydroxyl radicals alone

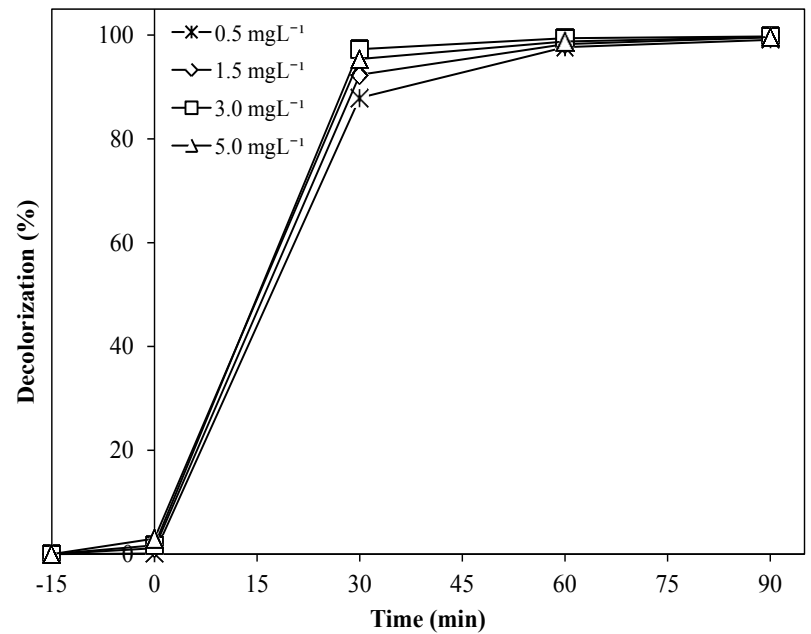

Figure 3e: Effect of Fe-HMS catalyst loading on catalytic degradation of RG-19. $\left(\mathrm{T}=40^{\circ} \mathrm{C}, \mathrm{pH} 3,\left[\mathrm{H}_{2} \mathrm{O}_{2}\right]=100 \mu \mathrm{L},[\mathrm{RG}-19]=100 \mathrm{mgL}^{-1}\right)$.

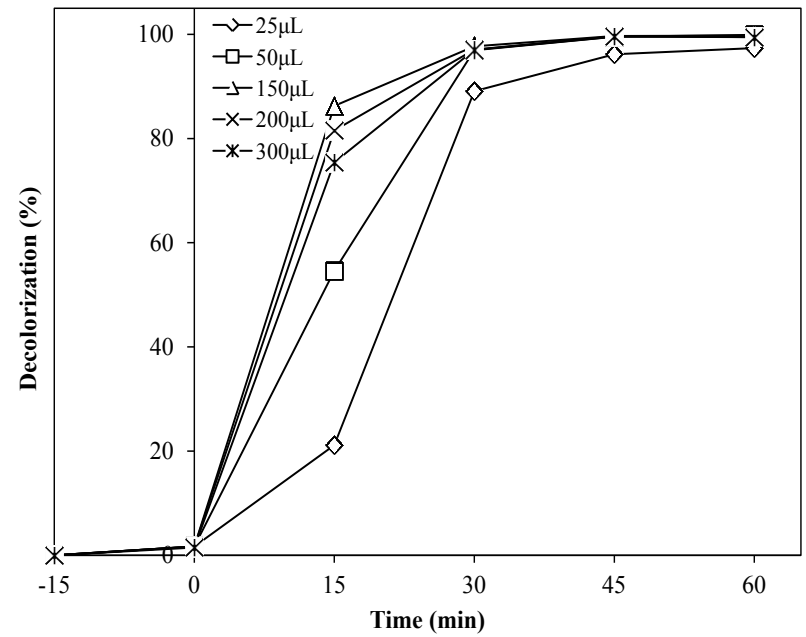

Figure 3f: Effect of hydrogen peroxide dosage on catalytic decolorozition of RG19. $\left(\mathrm{T}=40^{\circ} \mathrm{C}, \mathrm{pH} 3\right.$, Catalyst Dosage $\left.=3 \mathrm{mgL}^{-1},[\mathrm{RG}-19]=100 \mathrm{mgL}^{-1}\right)$. 


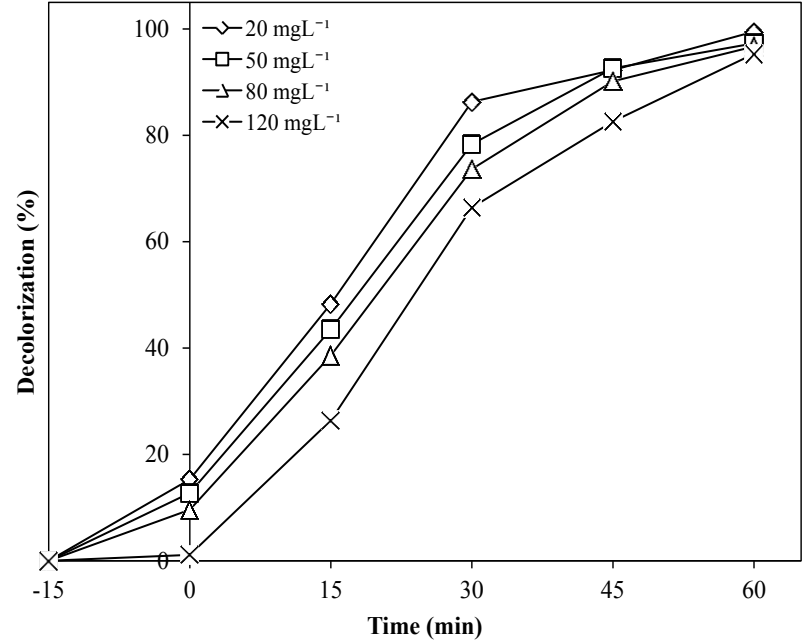

Figure 3g: Effect of initial concentration of dye on catalytic decolorization of RG$19\left(\mathrm{~T}=40^{\circ} \mathrm{C}, \mathrm{pH} 3\right.$, Catalyst Dosage $\left.=3 \mathrm{mgL}^{-1},\left[\mathrm{H}_{2} \mathrm{O}_{2}\right]=50 \mu \mathrm{L}\right)$

are not strong enough to attack dye molecules. This is in contrast with other samples as decolorazation shown are above 10 within these -15 minutes. Lower initial concentration of dye tends to result in faster decolorization even though with the absence of iron ions.

A series of experiments were then conducted at $\mathrm{pH} 3$ with variable of concentration from 20 to $120 \mathrm{mgL}^{-1}$ to study the effect of the model pollutant concentration. For, $120 \mathrm{mgL}^{-1}$ the decolorization process rather slowly with $95.3 \%$ decolorization within 60 minutes. Meanwhile, the lowest concentration $\left(20 \mathrm{mgL}^{-1}\right)$ resulted in almost $100 \%$ within the same time. Initial concentration of dye seemed to affect the Fentonlike oxidation reaction due to the percent of different amounts of dye molecules in the system. Since the dosage of Fe and hydrogen peroxide were fixed, the numbers of hydroxyl radicals remain the same. Thus, the same amounts of hydroxyl radicals would be used to attack higher number of dye molecules in the solution of $120 \mathrm{mgL}^{-1}$ dye.

Higher initial concentration of Reactive Green-19 could reduce the decolorization efficiency by approximately $1 \%$ for each initial concentration of dye and the obtained results were in good agreement with that reported by Zuorro and Lavecchia [30]. However, different types of dye have their own initial concentration and the best results for the rate of decolorization of Reactive Red 19 and Reactive Blue 19 were obtained with $50 \mathrm{mgL}^{-1}$ for dye concentration while it was $4 \mathrm{mgL}^{-1}$ for Amaranth Red Dye $[9,19,30]$. The lower number of dye molecules initially seemed to result in higher decolorization rate.

Effect of addition of salt: Salt also have been considers to effect wastewater treatment and one of the steps in dyeing industry involve the used a large amount of salt. In this study, the effect of addition of salt on decolorization of dye was assessed with $0,1.2,3.5,7.0$ and 11.7 $\mathrm{mgL}^{-1}$ of sodium chloride. The presence of $\mathrm{NaCl}$ at $1.2 \mathrm{mgL}^{-1}$ seemed to reduce the decolorization from $96 \%$ (without $\mathrm{NaCl}$ ) to only $42 \%$ within 60 minutes, to indicate significantly slower a slow motion of Fenton-like process. Other sample with $3.5 \mathrm{mgL}^{-1}$ of NaCl led to $35.5 \%$ decolorization within 60 minutes, followed by $7.0 \mathrm{mgL}^{-1}(32.6 \%)$ and $11.77 \mathrm{mgL}^{-1}(30.1 \%)$. The higher amount of salt used, the lower the decolorization rate. On the other hand, higher amount of salt did not significantly affect the absorption process in the first 15 minutes. In view of this, it is proven that production of anion $\left(\mathrm{Cl}^{-}\right)$has negative effect on the Fenton efficiency. Chloride ion has lower oxidation potential $(1.36 \mathrm{~V})$ than that of hydroxyl radical $(2.80 \mathrm{~V})$ it could lead to oxidation of chloride ion by hydroxyl radical. Thus, the amount that remained for the decolorization of dye could be reduced (Figure $3 \mathrm{~h}$ ).
The negative impact on Fenton-like oxidation was consistent with the result reported by Emami et al. [11]. Meanwhile, Abou-Gamra reported that Fenton-like reaction was unaffected if the concentration of $\mathrm{NaCl}$ was increased up to $0.340 \mathrm{mgL}^{-1}$. This was slightly different with the result in this study as salt kept on reducing the Fenton-like reaction effectiveness until $11.77 \mathrm{mgL}^{-1}$. The difference could be due to the difference in the structure of dye. Thus, the large amount of salt used in textile process negatively affected decolorization efficiency of dye molecules.

\section{Mineralization of reactive green-19}

By definition, chemical oxygen demand or COD is the amount of oxygen required to oxidize any organic matter in the water sample by means of a strong chemical oxidizing agent (potassium dichromate oxidation was used in this study). The initial COD of Reactive Green-19 obtained from this experiment was $222 \mathrm{mgL}^{-1}$, even though the initial concentration of dye used was $100 \mathrm{mgL}^{-1}$.

Results in Figure 4 indicate that the removal of COD increased with the cause of the reaction. However, decolorization efficiency was significantly higher than the COD removal with the percentage

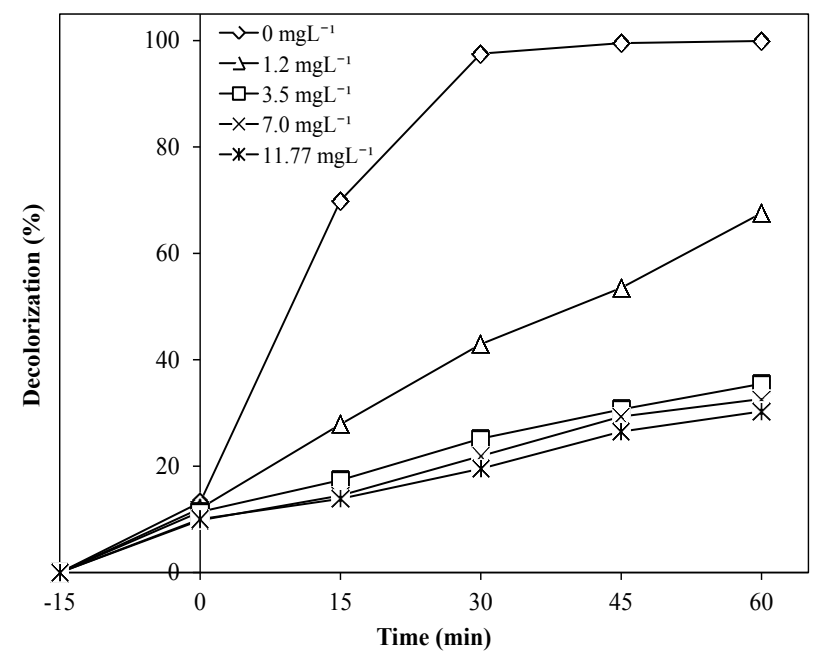

Figure 3h: Effect of addition of salt on catalytic decolorization of RG-19. $\left(\mathrm{T}=40^{\circ} \mathrm{C}, \mathrm{pH} 3\right.$, Catalyst Dosage $\left.=3 \mathrm{mgL}^{-1},\left[\mathrm{H}_{2} \mathrm{O}_{2}\right]=50 \mathrm{mgL}^{-1},[R \mathrm{R}-19]=100 \mathrm{mgL}^{-1}\right)$.

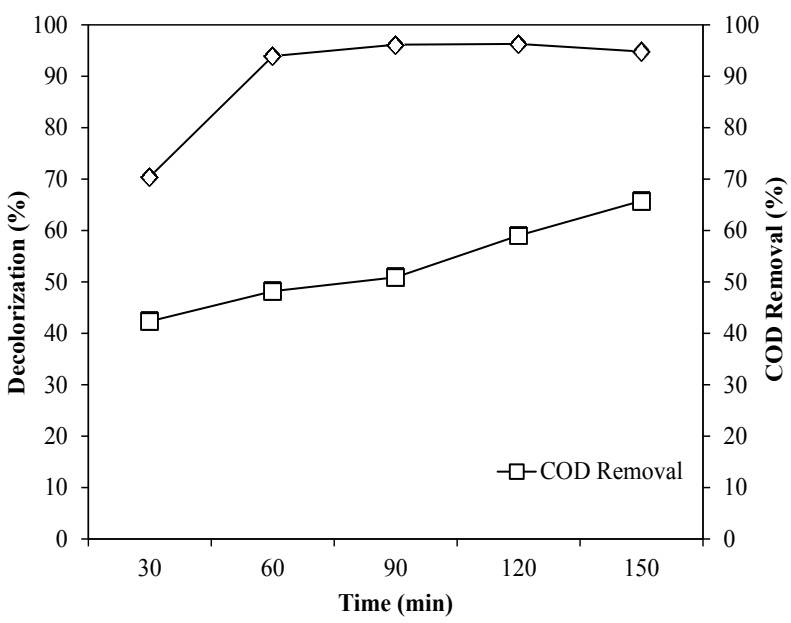

Figure 4: Decolorization versus mineralization of $\mathrm{RG}-19 .\left(\mathrm{T}=40^{\circ} \mathrm{C}, \mathrm{pH} 3\right.$, Catalyst Dosage $=3 \mathrm{mgL}^{-1}$, [H2O2] $=50 \mu \mathrm{L}$, [RG-19] $=100 \mathrm{mgL}^{-1}$ ). 
difference of $29 \%$ within 120 minutes. This could be due to the fact that although Reactive Green-19 dye had undergoes almost complete degradation, it was an incomplete oxidation of Reactive Green-19.

The result above can be verified from 'absorbance vs. wavelength' plot of shown in Figure 5. There are two peaks shown by the original sample (dye only) on Figure 5. The highest peak presents the wavelength for Reactive Green-19 dye, while second peak suggest complete mineralization did not take place. Subsequently, the initial of the second peak decreased with reaction time, when the mineralization process started to occur with the addition of the Fenton-like's reagent.

However, Zuorro and Lavecchia [30] mentioned that the COD removal for Reactive Green-19 dye only achieved above $70 \%$ after several hours. Even in some case, the mineralization percentage only approached $80 \%$ after 10 hours. Thus, COD removal could indicate the percent of mineralization that it depends on molecular structure of the organics themselves [30].

\section{Kinetic study for heterogeneous Fenton system}

Figure 6 shows the catalytic decolorization of Reactive Green-19 dye by using different types of the Fenton-like treatment. In the heterogeneous Fenton process (Fe-HMS catalyst and $\mathrm{H}_{2} \mathrm{O}_{2}$ ); faster decolorization was achieved, which also has higher value of constants for both first and second order models (Table 4). Besides, heterogeneous Fenton process itself has the combination process of adsorption and oxidation, which relied on availability of high surface area.

In this study, there were still slow reactions occurred with the presence of either Fe or $\mathrm{H}_{2} \mathrm{O}_{2}$ only, where the efficiency of Fenton-like oxidation decreased from $98 \%$ until $12 \%$ and $28 \%$ within 120 minutes. As discussed in earlier section (effect of addition of salt), the presence of chloride ions could reduce the effectiveness of Fenton-like oxidation. The difference of removal percentage with and without the presence of salt in the reaction is approximately 55\%, within 120 minutes (Figure 6).

The pseudo first and second-order plots are made using the equations. The linear trend line of $\left(\ln C_{o} / C_{t}\right)$ and $\left(1 / C_{t}-1 / C_{0}\right)$ against reaction time in Figure $7 \mathrm{a}$ and Figure $7 \mathrm{~b}$ gives the values of correlation coefficients, $\left(\mathrm{R}^{2}\right)$ and rate constant $(\mathrm{k})$ as summarized in Table 4 . The fastest decolorization, which involved the use of heterogeneous Fenton catalysts have higher values of $\mathrm{R}^{2}(>0.9399)$ and approaching 0.9599 for the pseudo first order model as compared to relatively poorer fittings to the pseudo second order model. The lowest $\mathrm{R}^{2}$ is shown by the reaction

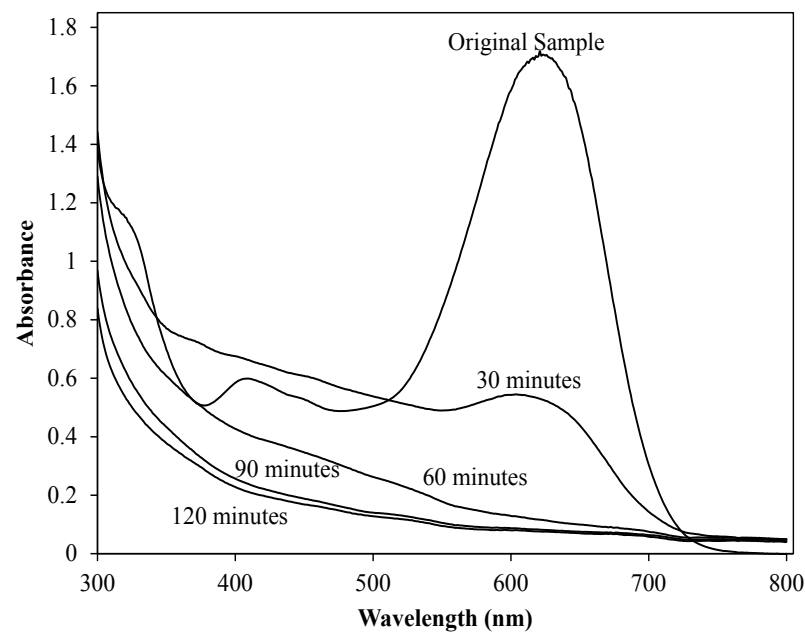

Figure 5: Wavelength measured for mineralization process.

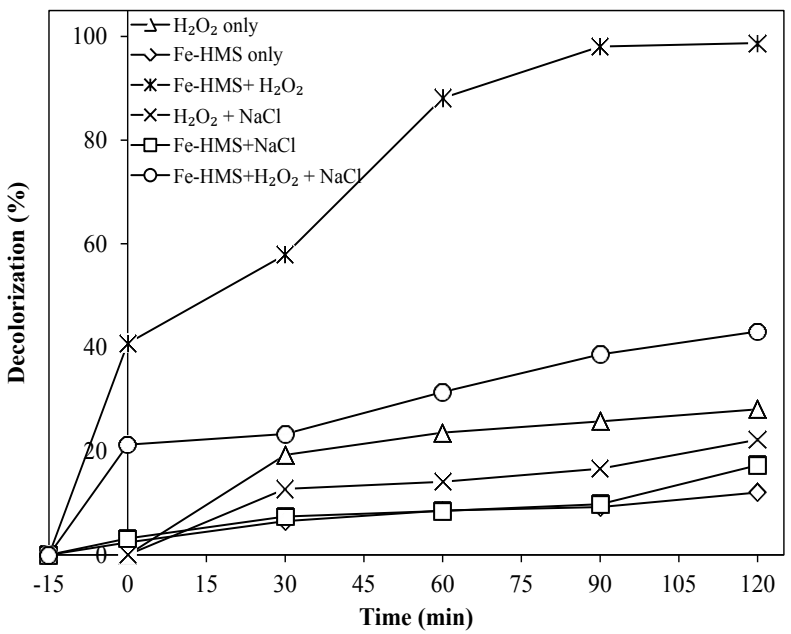

Figure 6: Comparison between different treatments on catalytic of RG-19 $\left(\mathrm{T}=40^{\circ} \mathrm{C}, \mathrm{pH} 3\right.$, Catalyst Dosage $\left.=3 \mathrm{mgL}^{-1},\left[\mathrm{H}_{2} \mathrm{O}_{2}\right]=50 \mathrm{mgL}^{-1},[R \mathrm{R}-19]=100 \mathrm{mgL}^{-1}\right)$.

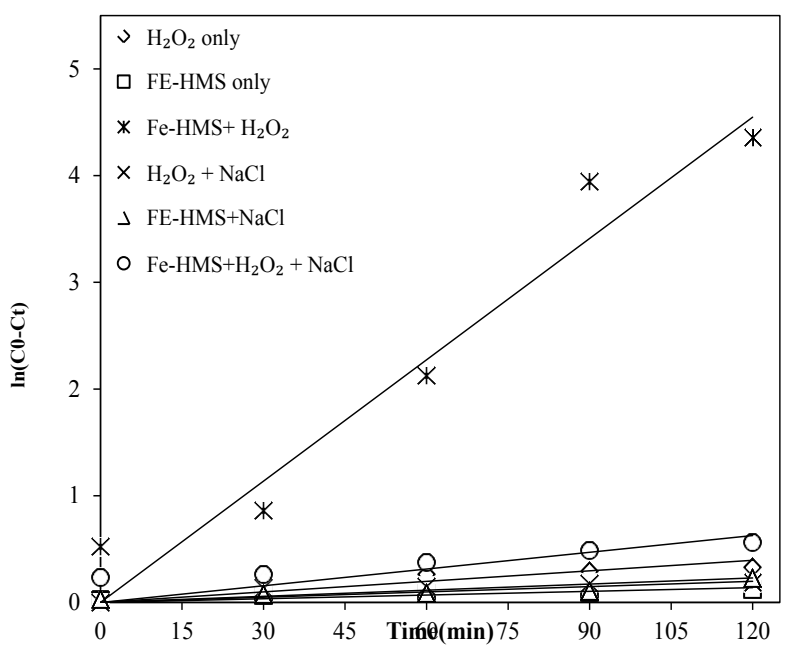

Figure 7a: First-order plots for Reactive Green-19 at various treatments $\left(\mathrm{T}=40^{\circ} \mathrm{C}, \mathrm{pH} 3\right.$, Catalyst Dosage $\left.=3 \mathrm{mgL}^{-1},\left[\mathrm{H}_{2} \mathrm{O}_{2}\right]=50 \mu \mathrm{L},[\mathrm{RG}-19]=100 \mathrm{mgL}^{-1}\right)$.

involving the use of hydrogen peroxide and salt, in which the value are 0.5831 for the first order model and 0.6112 for second order model.

The reaction by involving Fe-HMS catalyst, $\mathrm{H}_{2} \mathrm{O}_{2}$ and salt seems to favour the first order model on the basis of higher value of $\mathrm{R}^{2}$. This result is in a good agreement with the study by Olajire et al. reported higher correlation with the second-order reaction $[1,29]$.

\section{Reusability and stability of the catalyst studies}

The reusability of Fe-HMS catalyst was investigated by repetitive use of the catalyst, as shown in Figure 8. The catalyst was filtered and tested using atomic absorption spectrometer to detect the leaching of iron ions at the end of the process. The amount of Fe was $1.439 \mathrm{mgL}^{-1} \mathrm{Fe}$.

The reaction rates for the first two cycles were found to decrease due to the deactivation of the catalyst $[7,29,30]$. Nevertheless, the next two cycles showed the increment of the decolorization efficiency by approaching almost similar activity with the previous run. There was no color change in each cycle, where the original color of the catalyst was brown. The Fe-HMS catalyst could be reused with almost the same catalytic activity. 


\begin{tabular}{|c|c|c|c|c|}
\hline & \multicolumn{2}{|c|}{ 1st Order } & \multicolumn{2}{c|}{ 2nd Order } \\
\hline Types of treatment & $\mathbf{R}^{\mathbf{2}}$ & $\mathbf{k}_{\mathbf{1}}\left(\mathbf{m i n}^{\mathbf{1}} \mathbf{)}\right.$ & $\mathbf{R}^{\mathbf{2}}$ & $\left.\mathbf{k}_{\mathbf{2}} \mathbf{( \mathbf { L } \mathbf { ~ m } ^ { - 1 } \mathbf { ~ m i n }} \mathbf{- 1}\right)$ \\
\hline $\mathrm{H}_{2} \mathrm{O}_{2}$ only & 0.6699 & 0.0033 & 0.7219 & $4.0 \mathrm{E}-0.5$ \\
\hline $\mathrm{Fe}-\mathrm{HMS}$ only & 0.7816 & 0.0012 & 0.8014 & $1.0 \mathrm{E}-05$ \\
\hline $\mathrm{Fe}-\mathrm{HMS}+\mathrm{H}_{2} \mathrm{O}_{2}$ & 0.9399 & 0.0379 & 0.8045 & 0.0053 \\
\hline $\mathrm{H}_{2} \mathrm{O}_{2}+\mathrm{NaCl}$ & 0.5831 & 0.0019 & 0.6112 & $2.0 \mathrm{E}-05$ \\
\hline $\mathrm{Fe}-\mathrm{HMS}+\mathrm{NaCl}$ & 0.8374 & 0.0017 & 0.8316 & $2.0 \mathrm{E}-05$ \\
\hline $\mathrm{Fe}-\mathrm{HMS}+\mathrm{H}_{2} \mathrm{O}_{2}+\mathrm{NaCl}$ & 0.5889 & 0.0052 & 0.7309 & $7.0 \mathrm{E}-05$ \\
\hline
\end{tabular}

Table 4: Kinetic parameters for the reaction at various conditions.

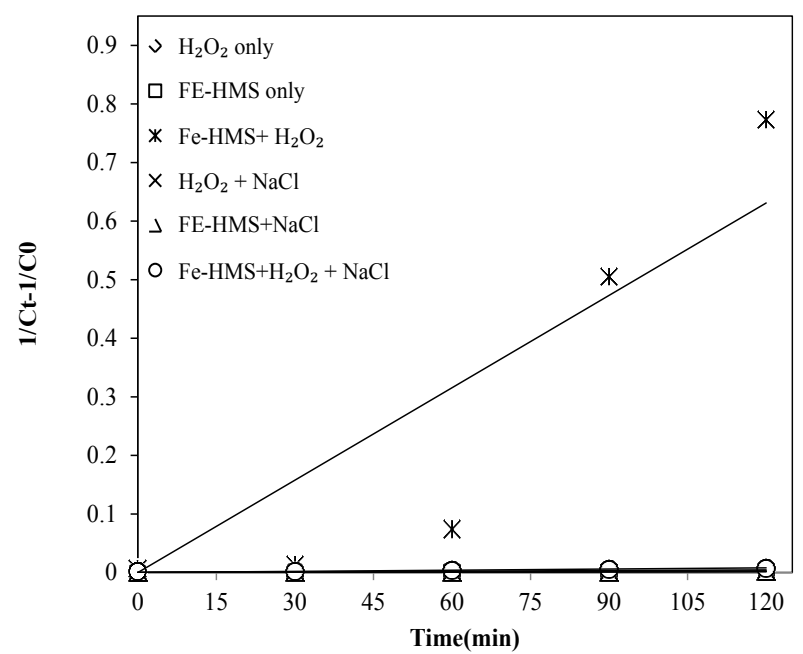

Figure 7b: Second-order plots for Reactive Green-19 at various treatments. $\left(\mathrm{T}=40^{\circ} \mathrm{C}, \mathrm{pH} 3\right.$, Catalyst Dosage $\left.=3 \mathrm{mgL}^{-1},\left[\mathrm{H}_{2} \mathrm{O}_{2}\right]=50 \mu \mathrm{L},[\mathrm{RG}-19]=100 \mathrm{mgL}^{-1}\right)$.

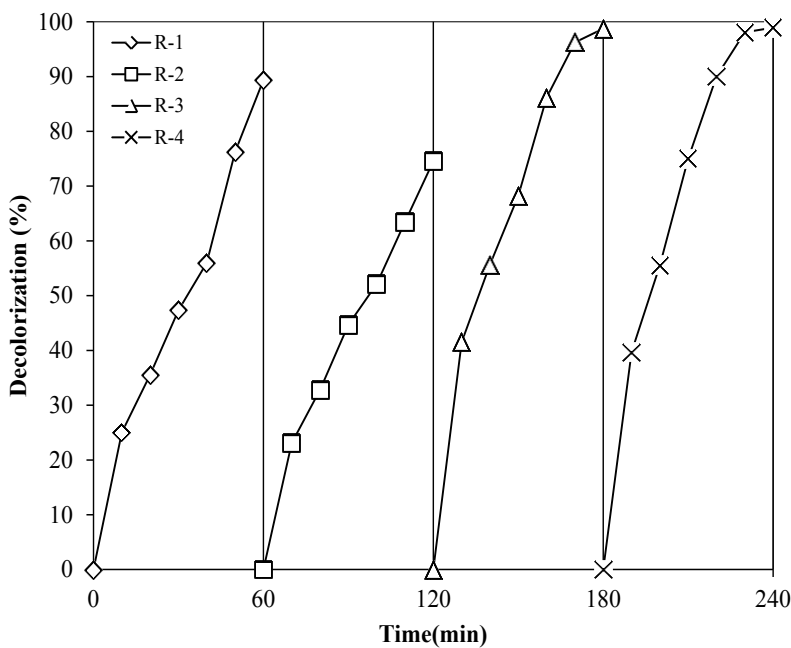

Figure 8: Reusability plot for decolorization of Reactive Green-19 $\left(\mathrm{T}=40^{\circ} \mathrm{C}, \mathrm{pH} 3\right.$, Catalyst Dosage $\left.=3 \mathrm{mgL}^{-1},\left[\mathrm{H}_{2} \mathrm{O}_{2}\right]=50 \mu \mathrm{L},[\mathrm{RG}-19]=100 \mathrm{mgL}^{-1}\right)$.

\section{Conclusions}

Condition in the preparation of iron-doped hexagonal mesoporous silica catalyst (Fe-HMS) using direct synthesis method was found to affect their catalyst activity. The presence of acid in the synthesis mixture could increase the reaction for up to a HCL concentration of $2 \mathrm{mgL}^{-1}$. Meanwhile, the addition of Fe ions above $7 \mathrm{wt} \%$ - Fe led to excellent improvement, in the efficiency. Thus, $13 \mathrm{wt} \%$ of Fe was selected as optimal level for the development of Fe-HMS catalyst. The characterization results suggested that little change in the synthesis condition of Fe-HMS catalyst, could lead to huge difference in the pore structure. The decolorization of Reactive Green-19 by the Fentonlike reaction was also studied by varying the experimental conditions. The most effective decolorization was achieved $\mathrm{pH} 3$ and reaction temperature of $40^{\circ} \mathrm{C}$ with near complete decolorization efficiency. By manipulating these parameters, the reaction time to reach complete decolorization was shorted from 120 minutes to 90 minutes. Meanwhile, the other optimal parameters were $3 \mathrm{mgL}^{-1} \mathrm{Fe}$ catalysts loading and the addition of $50 \mu \mathrm{L}$ of $\mathrm{H}_{2} \mathrm{O}_{2}$ solution. On the other hand, a small quantity of salt negatively affected the reaction. The kinetic study led to conditions that pseudo first order model accurately fits the date. The reusability potential of Fe-HMS catalyst was also proved using 4 cycle of catalytic runs with activity drop lower that $20 \%$.

\section{Acknowledgements}

A Research University Grant (814144) from Universiti Sains Malaysia and a PRGS Grant from Ministry of Higher Education (6762001) are gratefully acknowledged.

\section{References}

1. Olajire AA, Olajide AJ (2014) Kinetic Study of Decolorization of Methylene Blue with Sodium Sulphite in Aqueous Media: Influence of Transition Metal lons. J Phys Chem Biophys 4: 136.

2. Abou-Gamra ZM (2014) Kinetic and thermodynamic study for Fenton-like oxidation of Amaranth Red dye. Advances in Chemical Engineering and Science 3: 285-291.

3. Padhi BS, Ratna A (2012) Pollution due to synthetic dyes toxicity and carcinogenicity studies and remediation. Int J Environ Anal Chem 3: 940-955.

4. Aliyan H, Fazaeli R, Jalilian R (2013) $\mathrm{Fe}_{3} \mathrm{O}_{4} @$ mesoporous SBA-15: A magnetically recoverable catalyst for photodegradation of malachite green Appl Surf Sci 2: 147-153.

5. Babuponnusami A, Muthukumar K (2014) A review on Fenton and improvements to the Fenton process for wastewater treatment. J Environ Chem Eng 2: 557-572.

6. Behnajady MA, Modirshahla N, Ghanbary F (2007) A kinetic model for the decolorization of C.I. Acid Yellow 23 by Fenton process. J Hazard Mater 148: 98-102.

7. Tambe Patil BB (2015) Wastewater Treatment Using Nanoparticles. J Adv Chem Eng 5: 131.

8. Ahmadiab M, Ramavandic B, Sahebid S (2014) Efficient Degradation of a Biorecalcitrant Pollutant from Wastewater Using a Fluidized Catalyst-Bed Reactor. Chem Eng Commun 3: 18-1129.

9. Ertugay N, Acar FN (2013) Removal of COD and color from Direct Blue 71 azo dye wastewater by Fenton's oxidation: Kinetic study. Arabian J Chem.

10. Amani H, Ahmad Z, Hameed BH (2014) Synthesis of fatty acid methyl esters via the methanolysis of palm oil over $\mathrm{Ca}_{3.5 \mathrm{x}} \mathrm{Zr}_{0.5 \mathrm{y}} \mathrm{Al}_{\mathrm{x}} \mathrm{O}_{3}$ mixed oxide catalyst. Renewable Energy 66: 680-685.

11. Amani $\mathrm{H}$, Ahmad Z, Hameed BH (2014) Highly active alumina-supported Cs-Z mixed oxide catalysts for low-temperature transesterification of waste cooking oil. Appl Catal A Gen 487: 16-25.

12. Amani H, Ahmad Z, Asif M, Hameed BH (2014) Transesterification of waste cooking palm oil by $\mathrm{MnZr}$ with supported alumina as a potential heterogeneous catalyst. J Ind Eng Chem 20: 4437-4442.

13. El Haddad M, Regti A, Laamari MR, Mamouni R, Saffaj N (2014) Use of Fenton reagent as advanced oxidative process for removing textile dyes from aqueous solutions. J Mater Environ Sci 3: 667-674.

14. Amani $\mathrm{H}$, Asif M, Hameed $\mathrm{BH}$ (2016) Transesterification of waste cooking palm oil and palm oil to fatty acid methyl ester using cesium-modified silica catalyst. J Taiwan Inst Chem Eng 58: 226-234.

15. Babaeiab A, Babolib Z, Jaafarzadehab N, Goudarziab G, Bahramic M, et al (2013) Synthesis, performance, and nonlinear modeling of modified nano-sized magnetite for removal of $\mathrm{Cr}(\mathrm{VI})$ from aqueous solutions. Chem Eng Commun 3. 768-777.

16. Mota ALN, Albuquerque LF, Beltrame LTC, Chiavone-Filho O, Machulek Jr. A, et al. (2008) Advanced oxidation processes and their application in the petroleum industry: A Review. Brazilian Journal of Petroleum and Gas 2: 122 142. 
Citation: Ashikin SN, Amani H, Abdullah Z (2016) Catalytic Activity of Iron Doped Hexagonal Mesoporous Silica (Fe-HMS) for Degradation of Reactive Green-19 Dye in Water. Nat Prod Chem Res 4: 215. doi:10.4172/2329-6836.1000215

17. Taman R, Ossman ME, Mansour MS, Farag HA (2015) Metal Oxide Nano-particles as an Adsorbent for Removal of Heavy Metals. J Adv Chem Eng 5: 125.

18. Li Y, Feng Z, Lian Y, Sun K, Zhang L, et al. (2005) Direct synthesis of highly ordered Fe-SBA-15 mesoporous materials under weak acidic conditions. Microporous Mesoporous Mater 84: 41-49.

19. Mansoorian HJ, Bazrafshan E, Yari A, Alizadeh M (2014) Removal of Azo dyes from aqueous solution using Fenton and modified Fenton processes. Health Scope 2: 15-27.

20. Babaeiab A, Bahramic M, Firouzid A, Esfahanid A, Leila A (2014) Adsorption of cadmium onto modified nanosized magnetite: kinetic modeling, isotherm studies, and process optimization. Desalination Water Treat 3: 3380-3392.

21. Vinu A, Sawant DP, Ariga K, Hossain KZ, Halligudi SB, et al. (2005) Direct synthesis of well-ordered and unusually reactive FeSBA-15 Mesoporous Molecular Sieves. Chem Mater 17: 5339-5345.

22. Ghaly AE, Ananthashankar R, Alhattab M, Ramakrishnan VV (2014) Production Characterization and Treatment of Textile Effluents: A Critical Review. J Chem Eng Process Technol 5: 182.

23. Rahmat N, Abdullah AZ, Mohamed AR (2010) Mesoporous Santa Barbara Amorphous-15, types, synthesis and its applications towards biorefinery production. Am J Appl Sci 7: 1579-1586.
24. Erdem S, Erdem B, Oksuzoglu RM, Citak A (2013) Bifunctional Fe-SBA-15$\mathrm{SO} 3 \mathrm{H}$ Mesoporous catalysts with different $\mathrm{Si} / \mathrm{Fe}$ molar ratios: synthesis, characterization and catalytic activity. Bull Korean Chem Soc 5: 1481-1486.

25. Stasinakis AS (2008) Use of selected Advanced Oxidation Processes (AOPS) for wastewater treatment. Global NEST Journal 3: 376-385.

26. Pang YL, Abdullah AZ (2013) Current status of textile industry wastewater management and research progress in Malaysia. Clean (Weinh) 8: 751-764.

27. Zanchetta B, Chaud MV, Santana MHA (2015) Self-Emulsifying Drug Delivery Systems (SEDDS) in Pharmaceutical Development. J Adv Chem Eng 5: 130.

28. Montalbán MG, Collado-González M, Trigo R, Díaz Baños FG, Villora G (2015) Experimental Measurements of Octanol-Water Partition Coefficients of Ionic Liquids. J Adv Chem Eng 5: 133.

29. Yang X, Tian $P$, Zhang $X, Y u X$, Wu T, et al. (2014) The generation of hydroxy radicals by Hydrogen Peroxide decomposition on FeOCl /SBA-15 catalysts for phenol degradation. Reaction Engineering, Kinetics and Catalysis 3: 1-11.

30. Zuorro A, Lavecchia R (2013) Evaluation of $\mathrm{UV} / \mathrm{H}_{2} \mathrm{O}_{2}$ Advanced Oxidation process (AOP) for the degradation of diazo dye Reactive Green 19 in aqueous solution. Desalin Water Treat 52: 1571-1577. 